\title{
Cognitive, Metacognitive, and Social/Affective Strategies in Listening Comprehension and Their Relationships with Individual Differences
}

\author{
Fateme Serri \\ Islamic Azad University, Najafabad Branch, Najafabad, Iran \\ Email: fateme_serri@yahoo.com \\ Aliakbar Jafarpour Boroujeni \\ Sharekord University, Iran \\ Email: Aliakbar_Jafarpour@yahoo.com \\ Akbar Hesabi \\ English Department, University of Isfahan, Isfahan, Iran \\ Email: a.hesabi11@yahoo.com
}

\begin{abstract}
This study tries to investigate the relationship between learners' listening strategy use, cognitive, metacognitive, social/affective, while they listen to the texts and some of their individual differences. In order to study this relationship, 40 Iranian university EFL (English as a Foreign Language) students were surveyed with four structured questionnaires and an ILTES listening test. The questionnaires were Listening strategy use (Vandergrift, 1997), learning style (Soloman and Felder, 2001), motivation (adapted from Laine, 1988), and the Revised NEO- FFI. In order to comprehend whether there is a relationship between variables, and to see which group of individual differences use which listening strategy more, statistical analysis of Multiple Regression analysis, Chi Square test, one way ANOVA, at the $p<0.05$ level, were used. The results suggested that there was a significant relationship between the level of motivation and the listening strategies. After motivation, learning style, also, had some effect on the listening strategies use. The other variables had no significant effect on the use of the three listening comprehension strategies. In addition it should be mentioned that social/ affective strategy was omitted in the analysis because the mean of this strategy use was so low. It means that no individual groups used this kind of listening strategy. Finally, the aim of this article was to clarify on little-investigated area, namely, listening comprehension strategies and some individual differences, and the findings discussed in the area of English language teaching.
\end{abstract}

Index Terms — listening strategy, meta-cognitive, cognitive, social/affective, individual differences

\section{INTRODUCTION}

Listening comprehension is the most forgotten skills in second language acquisition. Unfortunately most often, it is supposed that listening comprehension is a passive activity, but contrarily, it is an "active process" because the listeners must recognize the differences among sounds, understand vocabularies and the grammatical structures, get the meaning of language input and other prosodic proof from the text, and they must save the information gathered long enough in their mind to interpret the context in which the communication take place. Shortly, listening is a complicated activity and difficult to understand that requires extremely a lot mental exertion (Holden, 2004, p. 257).

A mixed number of skills composed listening comprehension, and all of these skills according to Holden (2004) "play an important role in the process of language acquisition and the development of related language skills". So, having knowledge and the use of effective strategies in listening comprehension can help learners to understand most of language input to which they listen to. Although the number of studies in listening comprehension strategy instruction is limit but in these limited number of studies it is highly proved that learners can be taught the use of strategies and these strategies improved their listening comprehension (Liu, 2008). It is inferred from the strategies use by learners that the strategies develop learners' self regulated learning through learners selection of their goals, assign them (goals) in their learning, supervise their improvement of learning, and assess their learning results.

Among the strategies, O'Malley and Chamot's (1990, 1985) cognitive, metacognitive, and social-affective strategies, that are based on cognitive theory (Liu, 2008), seems to be the basic and three main category of strategies. It should be mentioned that although there are other strategies with other names (Griffith, 2004), but it doesn't mean that they differ in nature. They are just different in their names and in their classification that different researchers used them according to their survey's aims. And there are some learner's factors (individual differences) which affect their second language learning and their strategy choice (Azumi, 2008; Martinez, 1996). Accordingly, the researcher's purpose of this study 
direct toward the investigation of the relationships between learners' listening strategy use, according to O'Mally and Chamot's (1990) strategy classification, and some of the individual differences.

\section{LITERATURE REVIEW}

Listening has an important effect on communication, and as it was estimated by researchers that adults spend 40-50\% of their communication time on listening, $25-30 \%$ on speaking, 10-15\% on reading, and about $10 \%$ on writing, (Holden, 2004). So it is logical to pay more attention on teaching listening comprehension in EFL educational program and SLA research.

Yaoko Matsuoka (2009) cited from Richards (2003) that in the history of listening, in the 1970s, listening was a capability among separate skills, and then, in the $80 \mathrm{~s}$ and $90 \mathrm{~s}$, this idea changed to comprehension models in the field of cognitive psychology. Afterward, the difference between bottom up processing and top down processing was distinguished, and subsequently listening was considered as an explanatory process. Moreover, it was defined as the capability of understanding the spoken form of language that is used by native speakers. It was also more comprehensively defined by O'Mally, Chamot, and kupper (1989) that "listening comprehension is an active and conscious process in which the listener construct meaning by using cues from contextual information and from existing knowledge, which relying upon multiple strategies resources to fulfill the task requirement"(cited in Yaoko Matsuoka, 2009, p. 32).

In addition, listener must be able to process and guess the intended meaning of the string sounds of a spoken language in a particular discourse and condition. In other words, he must know "the illocutionary force of an utterance"(Matsuoka, 2009, P. 32).

The information processing in L2 or FL teaching and learning situation describe how learners deal with the information or the input that they encounter. Now, According to Liu (2008), Anderson (2005) divided the process of listening in to three stages within the area of FL/L2 teaching and learning: the perceptual, the parsing, and the utilization. During the perceptional process listeners concentrate consciously on the oral sounds of speech (e.g. intonation) and preserve them in their "echoic memory". But because of the limitation of the memory, listeners use their selective attention, and some parts of the information are lost by them. In order to understand the meaning of sounds, listeners' brain sends the information from echoic memory at once. In the second process, the parsing process, listeners put together the meaning of "the words of the original input in short term memory form meaningful mental representations". This meaningful information can be stored in short term memory. Finally in the last process, utilization, listeners' prior knowledge will be integrated with the incoming message, and if these two types of knowledge, the prior knowledge and the incoming message, match together, listening comprehension occurred. It should be mentioned that these three stages occur in a manner of repetition. It means that one stage change in to another stage and then back to the previous one again (p.86).

In addition, with considering the notion of processing, O'Malley and Chamot (1990) and O'Malley et al. (1985) recognized three basic types of strategies, that is to say, metacognitive, cognitive, and social strategies, which will be explained in the following part.

The metacognitive strategies refer to the actions that learners use consciously while listening to a spoken text attentively. Metacognitive strategies deal with knowing about learning. It means that learners learn how to learn with metacognitive strategies. With the help of this language learning strategy, learners are involved in thinking about the process of learning while they are planning, monitoring, and evaluating their own learning, exactly like pre tasks activities (Holden, 2004). Learners check up and appraise their comprehension of the listening text by the use of metacognitive strategies. On the other hand, the cognitive strategies are separate learning activities and they are basically activities that are used by learners in order to understand the linguistic input and get knowledge. For example, when a learner finds a difficult word in a text and inferring the meaning of that word from the context, in fact he used the cognitive strategy. In addition, cognitive strategies are those that control the input or use a certain skill to complete a particular task (Holden, 2004; Meang, 2006; Grifith, 2004; Azumi, 2008; Martinez, 1996). According to O'Malley and Chamot (1990), cognitive strategies are strategies that "reflect mental manipulation of tasks", such as practicing and analyzing, enable learners to understand and produce new language by many different ways. And the last one, social/affective strategies refers to strategies that learners use to learn by interaction with their classmates and questions that are asked from teacher to understand the special subject, or remove or lower their anxiety.

However, just a small number of researchers have tried to study the listening strategy use and L2 listening ability like Vandergrift (1997; 2003), Goh (2002) and Liu (2008).

A successful listener can focus on the subject he is hearing, design what to listen for, use both bottom-up processing (like textual cues) and top-down processing (like prior knowledge and experience). But unsuccessful listeners primarily use bottom-up processing, listen word by word, and use other strategies by chance. As Goh (2002) revealed in his research, more skillful listener adopts both cognitive and metacognitive strategies in order to understand most of the text that he listens for. He can also use his "prior knowledge of linguistic cues, and contextual information". Whereas less skillful listeners use just a number of strategies, and they frequently confused by unfamiliar words and phrases that they encounter in listening text (Liu, 2008, p. 87) 
The problem that lies in the study of teaching and language learning strategies is that most researchers select those strategies that seem to be as GLL strategies and want their participants to use those strategies. But, there are a number of factors that affect learners' strategy choice, and researchers/teachers don't pay attention to them. As Willing (1981) recommended "any training process to develop learning strategies has to take all such factors into consideration" (Martinez, 1996, p. 107). Some researchers have identified factors that affect on L2 listening comprehension, and they were mentioned in Qui Bie (2006). For example, Rubin (1994) was a researcher who identified five factors affecting listening comprehension, and researchers believe that these five factors have great influence on listening comprehension. These factors are:

1) the characteristics of the text such as speech rate, hesitation, level of perception, stress and rhythm of text, L1 and L2 differences, redundancy, the complexity of morpheme, the order of words, discourse markers, visual support, and modification of syntax;

2) the characteristics of speakers such as language proficiency and gender;

3) the characteristics of task such as task type;

4) the characteristics of listeners such as their memory, age, gender, attention, level of language proficiency, background knowledge, and learning disability in L1;

5) the characteristics of process such as "top-down, bottom-up, and parallel processing, listening strategies, and negotiation of comprehensible input"(pp.197-198).

It was also found in Yao's (1995) study that the speakers' accent, speed, choice of vocabulary, and the listeners' interest and background knowledge influenced listening comprehension. Among all of these factors, the most important and influential factors that affect learners listening comprehension was the speakers accent and speed. It was found in the students reports of listening comprehension that clear pronunciation and speed affected their comprehension very much(Yao, 1995).

For the purpose of this study, factors that affected on listening comprehension are individual differences of listeners.

Ellis (1994) asserted that individual differences connect with each other. For example, the utilization of a special learning strategy in a successful manner possibly increase learners' motivation and lessen their anxiety level, personalities of learners may affect their views and "affective reactions", and so forth (Takayo Nitta, 2006, p. 7). It should be mentioned that the individual differences that were focused on in this study were listeners' age, gender, level of motivation, learning style, and personality traits. By investigating other studies, it was less evident in the use of cognitive, metacognitve and social/affective strategies in listening comprehension in relation with the individual differences of the listeners. But the results of Lio's (2008) study, who tried to find the relationships of learning styles and cognitive, metacognitive and social/affective strategies in listening comprehension, revealed that communicative learners prefer to use cognitive, metacognitive, and social/affective listening strategies "flexibly and actively", authority oriented learners preferred to use cognitive strategies, concrete learners used social/affective strategies more, and analytic learners again favored to use cognitive strategies more.

\section{OBJECTIVES OF THE STUDY}

As it was mentioned before, this study aims at investigating the relationships between listeners' age, gender, motivation, language learning strategies, and personality traits on the use of the three main strategies, cognitive, metacognitive, and social strategies, in listening comprehension. Therefore this study tries to answer the following questions:

1. Is there any difference in the use of cognitive, metacognitive, and social/affective strategies in accordance with Individual differences of Iranian EFL?

2. Is there any relationship between application of these strategies and Individual differences of Iranian EFL listeners?

3. What are the predictors of individual differences in the use of cognitive, metacognitive and social/affective strategies in listening comprehension?

\section{METHOD}

\section{A. Participants}

The participants of this study were 40 upper-intermediate TEFL undergraduate students, consisting of 24 female and 16 male, and they were studying English in a nongovernment University. All participants were native speakers of Persian and ranged between 19 and 53 years in age. They formed up a representative sample of Iranian EFL learners. Furthermore, they learned English as a university subject for academic purpose - not for communicative purpose.

\section{B. Instrument}

There were five instruments that were used for collecting the data of this study: IELTS listening comprehension test, NEO questionnaire by Costa and McCrae (2004) for determining learners' personality traits, Soloman and Felder (2001) learning styles questionnaire, motivation questionnaire by Laine's (1988) to access learners' level of motivation, and another questionnaire for discovering learners use of cognitive, metacognitive and social/affective strategies by 
Vandergrift (1997). And finally, in order to know learners' age and gender, they were asked to write it down above the questionnaires.

\section{IELTS Listening Test}

This test consisted of 40 questions derived from Cambridge University press (2008) in order to determine learners' proficiency level of listen comprehension. There were fill-in-the-gap and multiple-choice questions, and the time that students need to complete it was about 30 minutes.

\section{NEO Questionnaire}

In this study, in order to determine learners' personality traits, NEO questionnaire with Persian adoption (Costa and McCrae, 2004) was used. The five aspects of personality that this inventory measured were Neuroticism, Extraversion, Openness, Agreeableness, and Conscientiousness. It consisted of 60 questions and the choices reflect a number of fivepoint Likert-type scale and ranged from strongly agree to strongly disagree. The participants selected the choices according to their preference toward the items. Each personality aspect was measured with 12 items. It should be mentioned that Garousi, Mehryar, and Ghazi Tabatabayi (2001) examined the reliability and validity of this inventory. "Cronbach's Alpha coefficients were between 0.66 and 0.87 " and the validity was "between 0.65 and 0.76 " (Zabihi, 2011, p. 3).

\section{Soloman and Felder's learning styles questionnaire}

Concerning the issue of learners' different learning styles, the material that was used to determining their learning styles was Soloman and Felder's (2001) questionnaire that consisted of 44 two choice items that identify eight distinct learning styles, but they are indicated by four pairs of mutual styles, that are active vs. reflective, sensitive vs. intuitive, visual vs. verbal, and sequential vs. global. This questionnaire was taken from Rahimi, Riazi and Saif (2008). They identified the reliability of the questionnaire within an acceptable range (.74)

\section{Laine's Motivation Questionnaire}

Another questionnaire that is used in this study check the motivation of the learners. It has been originally from Laine's (1988) model and adapted by Salimi (2000), but it was taken from, Riazi, Rahimi and Saif (2008). The participants choose a number of five-point Likert scales that represent the degree of their preference or tendency toward the items of questionnaire that are 36. Again, here the choices ranged from strongly agree to strongly disagree. In addition, the reliability of this questionnaire was determined by Riazi, Rahimi, and Saif (2008), and it was .80.

\section{Vandergrifts' Listening Strategy Questionnaire}

The last material was the strategy survey that determined learners' listening comprehension strategies that were applied by them. It consisted of 34 questions and they were designed to include metacognitive, cognitive, and social/affective strategies. The questions were originally adopted from Vandergrift (1997). The scores were on a fivepoint scale with strongly agree, agree, no opinion, disagree, strongly disagree. It should be mentioned, too, that the statements from 1 to 10 determined Metacognitive strategies use preference, 11 to 29 determined Cognitive strategies use preference, and the remaining ones determined social/affective strategies use preference. The reliability of this questionnaire was measured by Liu (2008) with the use of Cronbach alpha test and it was .92.

\section{Procedures}

The data of this study was collected in two different phases and sections. In the first phase, the participants were asked to participate in the listening proficiency test to determine their level of proficiency in listening comprehension. In the second phase, they were asked to answer the questionnaires during 45 minutes. Participants were notified that the report of this research is nameless and the results of the inventory do not change their university grades. But in order to motivate the participants to cooperate with researcher, they were told to write their email address if they like to know about their individual results.

\section{RESULTS}

Distribution of and differences in the use of the strategies in accordance with individual difference (Research question 1)

To examine the distribution of independent variables across listening strategy use and to see whether there is a difference in the use of cognitive, metacognitive and social/affective strategies in accordance with the learners' individual differences, Chi-Square tests were done. The results of the distribution and Chi-Square tests revealed there was no difference in the use of cognitive, metacognitive and social/affective strategies, and the use of listening strategies between learners with some IDs, and the use of the strategies were in the same proportion. In other words, the sample of learners in different groups of age, gender, level of motivation, learning styles, and personality traits used these strategies not differently according to their IDs and all of them used cognitive strategies more than metacognitive and social/affective strategies. Even, the frequency of the use of social/affective strategies by the learners was zero. It means that none of the learners used social/affective strategies and metacognitive strategies were used just by $5 \%$ of the learners, with no differences according to their IDs. Also, in spite of individual differences of the learners, all of them used cognitive strategies more than metacognitive and social/affective strategies (95\%).

Correlation between application of the strategies and individual differences of the learners (Research question 2) 
In order to examine whether there is a relationship between the use of cognitive, metacognitive and social/affective strategies in listening comprehension and the individual differences of the learners, Pearson product moment correlation was applied. The results show that there is a significant relationship between learners' level of motivation and the use of cognitive, metacognitive and social/affective strategies $(r=.276, \mathrm{p} \square 0.01)$ and there is a negative correlation between the learners' age and motivation ( $\mathrm{r}=-.284, \mathrm{p} \square 0.01$ ) but for other individual differences and the use of the listening comprehension strategies there was no relationships because $\mathrm{p}>0.01$ (see table 1 ).

TABLE 1.

CORRELATION BETWEEN THE LISTENING COMPREHENSION STRATEGIES AND THE INDIVIDUAL DIFFERENCES

\begin{tabular}{|l|l|l|l|l|l|}
\hline & The listening comprehension strategies & Level of motivation & Gender & Learning styles & Personality traits \\
\hline Level of motivation & $0.276^{*}$ & - & -0.117 & -0.012 \\
\hline Age & -0.68 & $-0.284^{*}$ & -0.61 & -0.032 \\
\hline Gender & 0.81 & - & - & - & -0.144 \\
\hline Learning styles & -0.13 & - & 0.075 & - \\
\hline Personality traits & -0.73 & - & - & - \\
\hline
\end{tabular}

*Show the existence significant relationship at the level of 0.01

Prediction of the listening strategies use by the learners' individual differences (Research question 3)

In order to analyze the data more, regression analysis was used. Regression analysis was used for proposing model, and the model predicts how much it can explain the variances in the dependant variable. In other words, it predicts which variables are important in predicting of the listening strategies (cognitive, metacognitive, and social/affective). Our model explained $5.6 \%$ of the variance in the listening strategy use (Adjusted $\mathrm{R}^{2}=.56, \mathrm{p}<0.05$ ) accounted for the independent variables. Moreover, the results revealed that only motivation and personality traits significantly predicted the use of the listening comprehension strategies. According to the table 2, motivation was the strongest predictor of the listening strategy use. It accounted for $29 \%$ of the variation ( $\mathrm{p} \square 0.05$ ), and it is significant unique contribution to the prediction of the listening strategy use.

TABLE 2.

THE RESULTS OF REGRESSION ANALYSIS FOR LEARNERS LISTENING STRATEGY USE AND THEIR IDS

\begin{tabular}{|l|l|l|l|}
\hline Predictors & T value & P & $B$ \\
\hline Age & 0.012 & 0.904 & 0.011 \\
\hline Motivation & 3.138 & 0.002 & 0.299 \\
\hline Learning styles & 0.322 & 0.148 & 0.029 \\
\hline Personality traits & -1.458 & 0.748 & -0.133 \\
\hline Gender & 0.621 & 0.536 & 0.56 \\
\hline
\end{tabular}

\section{DISCUSSION}

All the three null hypothesizes expressed at the beginning and investigated empirically statistically supported. The results indicated that there was no difference in the use of cognitive, metacognitive and social/affective strategies, and the use of listening strategies between learners with some IDs, and the use of the strategies were in the same proportion. The reason of such results may be due to the fact that the participants never instructed to use these strategies, especially cognitive and metacognitive strategies. In regard to social/affective strategies, the sympathy that should be existed between the learners and the teacher is not enough, so the learners may be shy or fear to ask their question from their classmates or teacher. Moreover, it can be said that the other reason of the result may be related to the learners' level of proficiency. As Liu (2008) realized that advanced listener use more combination of strategies, linguistic knowledge, and prior experiences.

In addition, the only variables, IDs, that related to the use of cognitive, metacognitive, and social/affective strategies of listening comprehension by the learners of this study was level of motivation, and it affects on the strategy use. To state the mater differently, higher motivated learners used these strategies more, and it had the highest correlation with the strategy selection ( $\mathrm{r}=0.276, \mathrm{p} \square 0.01$ ). Rahimi et al (2008), also, revealed that there is a strong relationship between level of motivation and the use of strategies. This fact was also discovered by Oxford and Nyikos (1989) (Rahimi et al, 2008). It was also revealed that there is a negative relationship between the level of motivation and the age of the learners. It means that learners with lower age were more motivated, and the level of motivation related to the age of the learners.

Similarly, it was discovered that level of motivation was the best predictors of the selection of cognitive, metacognitive, and social/affective strategies which explained $29 \%$ of the variance in the strategy selection. So, it can be asserted that motivation is an important potential factor in an EFL context, and it can stimulate learners to persist both in L2 learning and possibly L2 listening comprehension. According to Dörnyei (2005), "motivation not only provides learners with driving force in language learning, but also can compensate for some personal or situational efficiencies faced by learners"( Peng, 2007).

So, in regard to the results of this study, teachers can teach EFL learners cognitive, metacognitive, and social/affective strategies in listening comprehension task regardless of their different personality traits, learning styles, 
ages, gender, and want all of them to use these strategies. In other words, these variables don't relate to the kind of these strategies selection, and as it was seen in the results, all the sample learners with the IDs used cognitive, metacognitive, social/affective strategies in a same proportion without any differences. But, as the last point, it should be said that much more researches need to be done in regard with individual differences and the kind of strategies that are used by learners, in a group with more students and other material of data collection.

\section{REFERENCES}

[1] Azumi, K. (2008). An Experimental Study of Language Learning Strategies: Particular Focus on the Patterns of Strategy use by Japanese university Learners of English 7(17), 149-169.

[2] Bie, Q. (2006), An Investigation of English Listening Strategies used by continuous education Program Students in Taiwan, 95205.

[3] Griffiths, C. (2004), Language Learning Strategies: Theory and research, New Zealand. Occasional Paper, 1, 1-25.

[4] Goh, C.C. (2002), Learners' Self Report on Comprehension and Learning Strategies for Listening. Asian Journal of English Language Teaching, 12, 45-68.

[5] Holden, W.R. (2004). Facilitating Listening Comprehension: Acquiring Successful Strategies. Bulletin of Hokuriku University, $28,257-266$.

[6] Liu, H. (2008). A Study of the Interrelationship between Listening Strategy Use, Listening proficiency, And Learning Style. ARECLS, 8, 84-104.

[7] Mccrae, R. R., \& Costa, P. T. (2004). A contemplated revision of the NEO Five-Factor Inventory. Personality and Individual Differences 36(3), 587-596

[8] Matsuoka, Y. (2009). Possible strategies for listening comprehension: Applying the concepts of conversational implicative and adjacency pairs to understand speaker intention in the TOEFL listening section. Accents Asia 3(2), 27-56.

[9] Martinez, I.M (1996). The Importance of Language Learning Strategies in Foreign Language Teaching. Cuadernos of English Philology 5(1), 103-120.

[10] Meang, U.K (2006). Comparison of L2 Listening and Reading Comprehension Strategies: A Case Study of Three Middle School Students. The Journal of Curriculum \& Evaluation 9(2), 471-500.

[11] Nitta, T. (2006). Affective, Cognitive and Social Factors Affecting Japanese Learners of English in Cape Town, 1-117.

[12] O’Malley, J.M., Chamot, A.U., Stewner-Manzanares, G., Küpper, L. \& Russo, R.P., (1985). Learning Strategy Applications with Students of English as a Second Language. TESOL QUARTERLY, 19(3), 557-584.

[13] O'Malley, J.M. and Chamot, A.U., (1990). Learning strategies in second language acquisition. London: Cambridge University Press.

[14] Peng, J. (2007). Willingness to Communicate in an L2 and Integrative Motivation among College Students in an Intensive English Language Program in China. University Of Sydney Papers in TESOL, 2, 33-59.

[15] Rahimi, M., Riazi, A. \& Saif, SH. (2008). An Investigation into the Factors Affecting the Use of Language Learning Strategies by Persian EFL. Canadian Journal of Applied Linguistics (CJAL), 11(2), 31-60.

[16] Rajamoney, SH. (2008). A Study on the Use of Language Learning strategies After Strategy Training among Four ESL Students: A case Study. 1- 153.

[17] Rubin, J. (1994). A Review of Second Language Listening Comprehension Research, The Modern Language Journal, 78(2), 199-221.

[18] Vandergrift, L., (1997). The strategies of second language (French) listeners. Foreign Language annals 30(3), $387-409$.

[19] Vandergrift, L., (2003). Orchestrating Strategy Use: Toward a Model of the Skilled Second Language Listener. Language Learning 53(3), 463-496.

[20] Yao, C.K. (1995), Needs Analysis of Freshman English Listening Curriculum. Papers from the Twelfth Conference on English Teaching and Learning in the public of China, 80-96.

[21] Zabihi, R. (2011). Personality in English Language Proficiency and Achievement. Wilolud Journal, 4(1), 1-6.

Fateme Serri was born in Najafabad, Iran in 1984. She received her BA degree in TEFL from Islamic Azad University of Najafabad, Isfahan, Iran in 2007.And now; she is going to finish her MA studies in TEFL from Islamic Azad University of Najafabad till February 2012. Her areas of interest are psycholinguistics, applied linguistics, and teaching English.

Aliakar Jafarpour Boroujeni received his PhD in TEFL from Isfahan University in 2005. He is an assistant professor at the university of Shahrekord. He has published a writing textbooks for the English major students entitled "The Essentials of Paragraph Writing", and an ESP textbook for the students of agricultural economics.

He has recently published two papers in Asian EFL Journal and Tabriz Research Journal of Humanities. His areas of interest are second language research and methodology, ESP and corpus linguistics. 


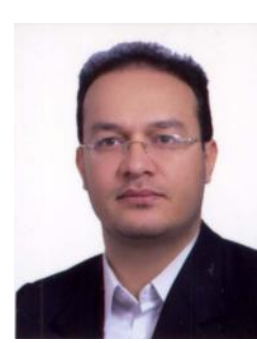

Akbar Hesabi has $\mathrm{PhD}$ in linguistics and currently works as a lecturer at English Department, University of Isfahan, Iran.

His areas of interest include Linguistics, neurolinguistics, and teaching English. He has published several articles in these areas. 